\title{
A Unified Format for Manuscript Structure, Style and Reference Citation across the Journals
}

\author{
Manoj Kumar Jaiswall ${ }^{1,2 *}$ and Ram Nath Jaiswal ${ }^{3}$ \\ ${ }^{1}$ Department of Psychiatry, Icahn School of Medicine at Mount Sinai, USA \\ ${ }^{2} J a m e s$ J Peters VA Medical Center, USA \\ ${ }^{3}$ Independent Scholar and Educator, India
}

Submission: January 16, 2018; Published: May 01, 2018

*Corresponding author: Manoj Kumar Jaiswal, Department of Psychiatry, Icahn School of Medicine at Mount Sinai One Gustave L Levy Place, New York, NY 10029-6574, USA, Email: manoj.jaiswal@mssm.edu

Keywords: Author; Manuscript; Journal publication; Format; Reference; Style; Guidelines; Instructions; Policy

\section{To the Editor}

Recently two correspondences in nature [1,2] suggested that all scientific and biomedical journals should do their own formatting and consider uniform style for all journals. As a neuroscientist these correspondence immediately got my attention and thinking about the time we waste on submission of the same research paper to multiple different journals each with their own format and reference style requirements.

For decades almost every journals even within same publishing house different journals have different format, structure, layout, and reference style for the authors to follow as a guidelines for manuscript preparation [3]. Although there are some common formatting styles and most of the basic science research papers are generally presented under the section: Title, Abstract, Introduction, Methods and Materials, Results and Discussion, the style and sequence of presentation are different. For example, Cell Press has their own format under the subtitle: Title, Summary, Abstract (including graphical abstract), Highlights, Introduction, Results, Discussion and STAR Methods. In contrast, "Springer Nature" does not use Abstract or Introduction headings; and for many neuroscience journals of "Springer Nature", Method section came at the end after the rest of the article. Similarly, journal "Science" papers are generally presented under the section title: Title, One Sentence Summary, Abstract, Main Text (containing introduction, experimental findings, and discussion) but without subheadings. Unfortunately, even the same publishers e.g. Elsevier have different formatting styles for their different flagship journals.

Similarly, Journals has their own reference styles for paper citations. For example my review article [4] cited in 2 biomedical journals differently, shown below [4].

\section{Box 1:}

Four major advantages of unified format for manuscript structure and reference

1. Saving huge amount of researchers time

2. Saving grant money and resources

3. Less burden to manuscript/journal pier review

4. Quick publication turnaround

Jaiswal MK Selective vulnerability of motoneuron and perturbed mitochondrial calcium homeostasis in amyotrophic lateral sclerosis: implications for motoneurons specific calcium dysregulation. Mol Cell Ther [4].

Whether my paper cited as above or using any other journal's defined alternatives in formatting style, name initials, publication year, journal name and page length, I don't see any major advantage of it. I believe publishing house, scientific society and journals are asking for individual formatting layout as a unique attribute. Journals editorial board and reviewers expect proper layout and format specified for their journals. Most often they are confused or annoyed when a submitted manuscript is incorrectly formatted and flawed in this regard and quite often manuscript risks immediate rejection irrespective of its scientific content (Illustration, Figure 1). Researcher like us spend days to weeks altering the format and reference style with the same data set and core idea to fit the new journal's style and their define limited word, sentence and character resulting in a waste of time, money and some time danger of loosing the story, science and message all together due to limitations of manuscript words or characters. In my opinion, thousands of dollars and vast amount of researcher's time spent on formatting the manuscript 
for specific journal during the submission avoided if the Journals, scientific society and community could be consent on a unified format, style and reference for all journals. Reviewers should be asked to judge submitted paper based on quality of research, original idea, and scope for a journal and not based on font, reference style, abstract length or even whether or not the method section appear before results and discussion section or after it. I see no scientific advantage or logic in it.

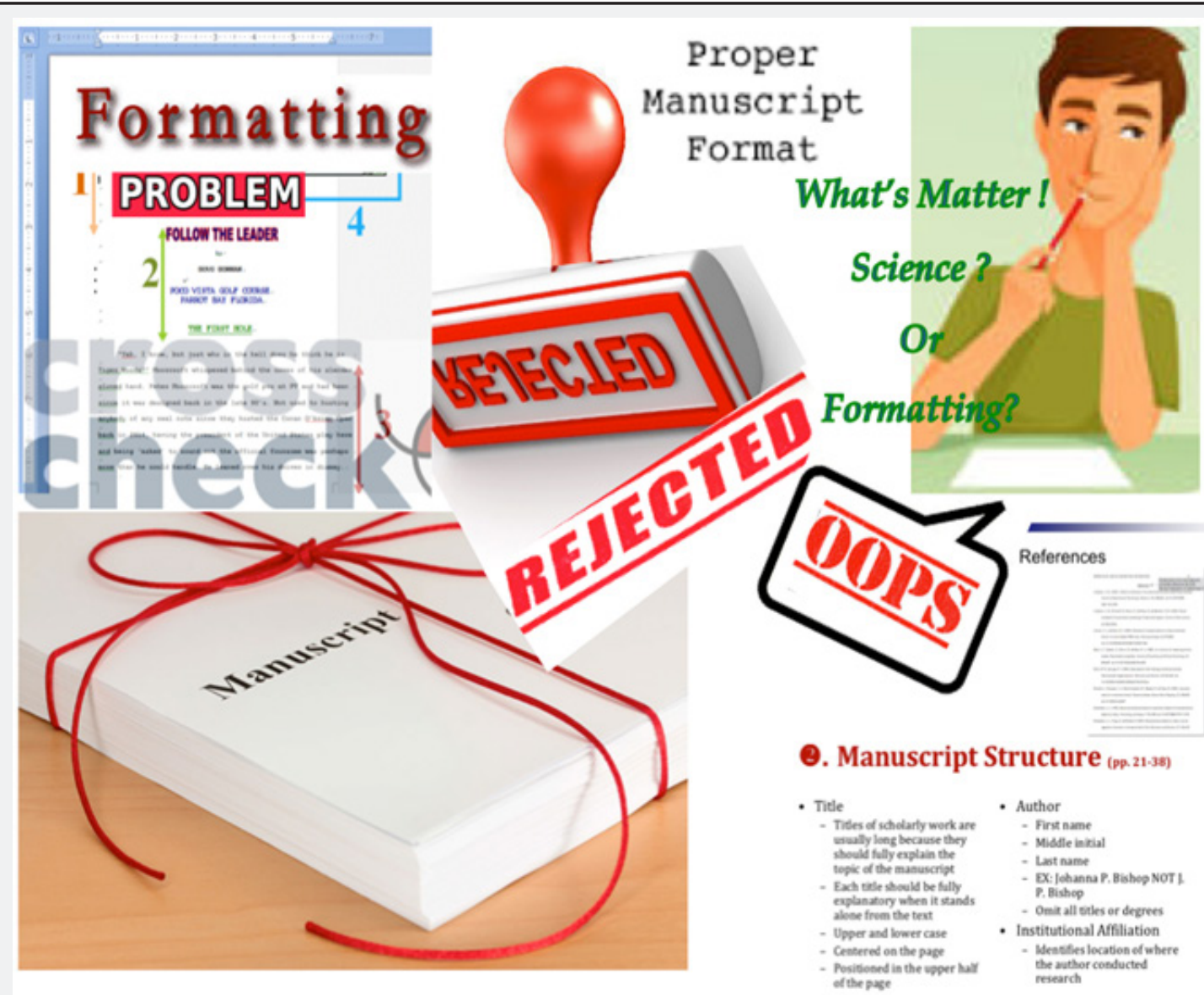

Figure 1: A cartoon illustrating real life frustrations of researchers dealing with individualized formatting style and citations/references while the manuscript going back and forth through several journals submission system.

Currently publishing practices across the journals waste researchers thousands of hour of productive research time while the manuscript going back and forth through several journals' individualized formatting styles for citations/references. While there are several softwares e.g. Endnote, ReadCube, Reference manager, Mendey Bib TeX, Ref Man and Ref Works which are commercially available for reference management, but most of them are costly and not readily available for many researchers from economically disadvantage countries. The core component of any biomedical and Science paper is same across the major journals. A unified format for manuscript reference citation across the journals would save huge amount of time, money, less burden to journal pier review, and quick publication turnaround time and a win-win situation for everybody including researchers, publishers and society as outcome of the research readily available to public who funds our research. Journals can achieve these goals by technology driven automated formatting, similar to automated manuscripts submission and reviewer's platform used by Frontiers [5] and implementation of software LateX as well as policy recently adopted by EMBO Press [6] which require reformatting only after acceptance of manuscript. I suggest scientific society and publishers to give us more meaningful reason why we should not opt for a single paper submission format and reference style. We really need to ponder upon this if we keep continue wasting our most valuable resource i.e. time for such redundant work and what is the actual cost of this practice by us and what this practice is actually costing as a scientific community and stakeholders at large.

\section{Author Contributions}

All authors listed, have made substantial, direct and intellectual contribution to the manuscript, and approved it for publication.

\section{Disclaimer}

The views expressed in this article are those of the authors and do not reflect the official Policy or position of the Icahn School of medicine at Mount Sinai or James J. Peters VA Medical Center. 


\section{Conflict of Interest Statement}

The authors declare that the research was conducted in the absence of any commercial or financial relationships that could be construed as a potential conflict of interest.

\section{Acknowledgments}

We would like to thank Dr. Ananta Paine and Sonia for comments on the manuscript.

\section{References}

1. Guo Q (2016) Publishing: Journals, agree on manuscript format. Nature 540: 525 .

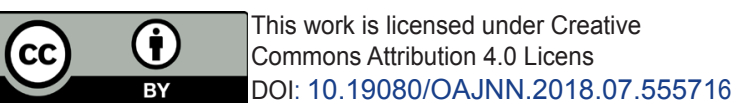

2. Moore JP (2017) Publishing: Journals, do your own formatting. Nature 542: 31 .

3. Strunk W, White EB (1979) The elements of style: [with index], (Macmillan Publishing Co; Collier Macmillan Publishers, London, New York, USA.

4. Jaiswal MK (2014) Selective vulnerability of motoneuron and perturbed mitochondrial calcium homeostasis in amyotrophic lateral sclerosis: implications for motoneurons specific calcium dysregulation. Mol Cell Ther 2: 26.

5. http://home.frontiersin.org

6. www.embo.org/embo-press

\begin{tabular}{l} 
Your next submission with Juniper Publishers \\
will reach you the below assets \\
- Quality Editorial service \\
- Swift Peer Review \\
- Reprints availability \\
- E-prints Service \\
- Manuscript Podcast for convenient understanding \\
- Global attainment for your research \\
- Manuscript accessibility in different formats \\
( Pdf, E-pub, Full Text, Audio) \\
- Unceasing customer service \\
Track the below URL for one-step submission \\
https://juniperpublishers.com/online-submission.php \\
\hline
\end{tabular}

